ARAÚJO, A.M.S. Acupuntura nas desordens reprodutivas (Revisão). PUBVET, Londrina, V. 8, N. 18, Ed. 267, Art. 1776, Setembro, 2014.

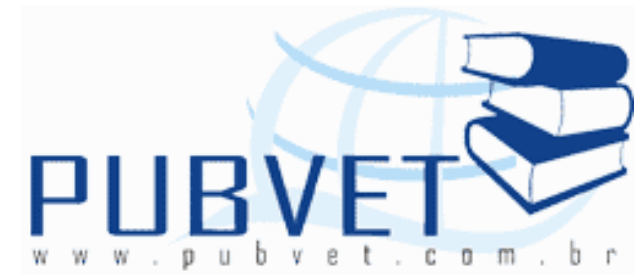

PUBVET, Publicações em Medicina Veterinária e Zootecnia.

\title{
Acupuntura nas desordens reprodutivas (Revisão)
}

Amanda Melo Sant'Anna Araújo

Médica Veterinária formada na Universidade Federal Rural do Rio de Janeiro, Especialista em Acupuntura pelo Instituto de Acupuntura do Rio de Janeiro e Mestre em Ciência Animal pela Universidade Estadual do Norte Fluminense.

\section{Resumo}

A estacionalidade dos acasalamentos, na maioria das espécies, é dependente da duração da gestação. Nos eqüinos, com gestação próxima a um ano, a cobertura e o nascimento dos potros acontecem na primavera e no verão, período do ano que oferece melhores condições ambientais para a sobrevivência da espécie (disponibilidade de alimentos, temperatura, luminosidade, etc.). O início da gestação em qualquer espécie, e em particular na eqüina, é marcado por vários acontecimentos. Durante esse período o útero e os ovários da égua, assim como o embrião, passam por várias modificações, adaptando-se à nova condição. Entre essas modificações cita-se a alteração dos níveis séricos de progestágenos e estrógenos. A acupuntura é um dos métodos mais antigos de tratamento médico. A prática da acupuntura veterinária é provavelmente tão antiga quanto a humana. Na verdade, o campo da acupuntura veterinária começou com o tratamento de cavalos, por causa de sua importância numa economia baseada em guerras e agricultura. A estimulação por agulhas em certos pontos, como o Bai Hui e VG2, estão 
ARAÚJO, A.M.S. Acupuntura nas desordens reprodutivas (Revisão). PUBVET, Londrina, V. 8, N. 18, Ed. 267, Art. 1776, Setembro, 2014.

historicamente associados com a reprodução e sabidamente altera os níveis plasmáticos de hormônio luteinizante (LH), hormônio folículo estimulante (FSH), estradiol, progesterona e testosterona. De acordo com a Medicina Tradicional Chinesa as funções reprodutivas dependem de um complexo de funções cooperativas que envolvem os órgãos internos, o Qi-Xue, os meridianos, especificamente os órgãos do aparelho reprodutivo.

Palavras-chave: hormônios, tratamento, agulha, reprodução

\section{Acupuncture in equine reproductive disorders (Review)}

\section{Abstract}

The seasonality of matings, in most species, is dependent on the duration of pregnancy. The equine pregnancy with the next one year, the coverage and the birth of foals happen in the spring and summer period of the year that offers better environmental conditions for species survival (food availability, temperature, light, etc.). The beginning of pregnancy in any species, and in particular in the equine, is marked by several events. During this period the uterus and the ovaries of the mare, and the embryo undergo several changes, adapting to the new conditions. Among these modifications can mention the change of serum estrogens and progestins. Acupuncture is one of the oldest medical treatment methods. The practice of veterinary acupuncture is probably as old as human. In fact, the field of veterinary acupuncture began with the treatment of horses, because of their importance in wars and agriculture based economy. The stimulation by needles at certain points, such as Bai Hui and VG2 are historically associated with reproduction and knowingly alters plasma levels of luteinizing hormone (LH), follicle stimulating hormone (FSH), estradiol, progesterone and testosterone. According to the ERM reproductive functions dependent on a cooperative complex functions involving internal organs, Qi -Xue, meridians, specifically of the reproductive organs.

Keywords: hormones, treatment, needle, reproduction 
ARAÚJO, A.M.S. Acupuntura nas desordens reprodutivas (Revisão). PUBVET, Londrina, V. 8, N. 18, Ed. 267, Art. 1776, Setembro, 2014.

\section{INTRODUÇÃO}

A estacionalidade dos acasalamentos, na maioria das espécies, é dependente da duração da gestação. Nos eqüinos, com gestação próxima a um ano, a cobertura e o nascimento dos potros acontecem na primavera e no verão, período do ano que oferece melhores condições ambientais para a sobrevivência da espécie (disponibilidade de alimentos, temperatura, luminosidade, etc.)

Entre os fatores que determinam a atividade sexual sazonal, podemos destacar o fotoperíodo e a sua interação com os fatores ambientais que, de alguma maneira, estabelecem as condições nutricionais das éguas. Embora exista uma estreita relação entre o aumento da duração da luminosidade diária, durante os meses de primavera e verão, e uma proporcional ativação dos mecanismos envolvidos na atividade reprodutiva, em diferentes latitudes, a condição nutricional das fêmeas tem uma importante participação na manifestação e regularidade dos ciclos estrais.

O início da gestação em qualquer espécie, e em particular na eqüina, é marcado por vários acontecimentos. Durante esse período o útero e os ovários da égua, assim como o embrião, passam por várias modificações, adaptandose à nova condição. Entre essas modificações cita-se a alteração dos níveis séricos de progestágenos e estrógenos.

Segundo um estudo feito pelo Centro de Estudos em Ecônomia Aplicada da ESALQ, dentre os diversos segmentos do complexo do agronegócio do cavalo destaca-se o turismo rural e atividades eqüestres, com uma estimativa de mais de 100 mil usuários, movimentação de cerca de $R \$ 21$ milhões e geração de aproximadamente 1.500 postos de trabalho no país.

Vários aspectos da endocrinologia reprodutiva são únicos aos eqüídeos. Enquanto as outras espécies animais, como bovinos, suínos e ovinos, foram altamente selecionados em função da eficiência reprodutiva, bem como de outras características produtivas, a habilidade de andar e de correr foi a única seleção pela qual os eqüídeos passaram. 
ARAÚJO, A.M.S. Acupuntura nas desordens reprodutivas (Revisão). PUBVET, Londrina, V. 8, N. 18, Ed. 267, Art. 1776, Setembro, 2014.

Na espécie eqüina, a transferência de embriões tem sido a solução mais utilizada para aumento do número de descendentes/ano/matriz. No cenário mundial, o Brasil ocupa posição de destaque ( $3^{\circ}$. lugar), acompanhando os dois líderes (Estados Unidos e Argentina) na utilização desta técnica (SQUIRES et al., 2003) citados por CAIADO et al. (2003).

Embora nos últimos anos, avanços indiscutíveis tenham sido atingidos com aprimoramento de técnicas reprodutivas, muitos ainda são os estudos feitos para a compreensão dos mecanismos básicos envolvidos no simples fato do surgimento de um novo indivíduo. Invulneráveis interesses movem a pesquisa, e não poderia ser diferente para aqueles que desejam ter uma eficiência máxima na criação e produção de eqüinos.

Ao longo das dinastias chinesas, vários escritos foram surgindo tanto da acupuntura humana quanto da veterinária, sendo o mais importantes deles o Hung-di Ne-Jing (The Yellow Empero's Classic of Internal Medicine) escrito no século III a.C. pelo imperador Huang Di. Existem descrições mostrando soldados fazendo acupuntura em seus cavalos, na dinastia CHO, 200 d.C. No Japão e na Europa existem citações na literatura desde meados de 1800 d.C. Os conceitos preconizados pela Medicina Tradicional Chinesa (MTC), são na maioria das vezes conflitantes com os conceitos de medicina ocidental.

Empregando-se a medicina ocidental, geralmente os problemas reprodutivos são tratados com a administração de grandes quantidades de hormônios ou pela remoção do órgão ou gônada afetada. A reposição hormonal é feita com o objetivo de restabelecer o eixo hipofisáriohipolatâmigo-gonadal, porém o que ocorre é uma superestimulação deste eixo sem levar em conta sua natureza sensível. Tudo isso pode levar ao aparecimento de efeitos colaterais, desequilíbrios hormonais futuros e esterilidade.

A carência em Medicina Veterinária de estudos com terapêuticas de baixo custo e alta eficiência como a acupuntura, relacionadas à fertilidade, principalmente no que diz respeito ao tratamento das patologias reprodutivas de éguas, vem despertando elevado interesse no meio científico, uma vez que 
ARAÚJO, A.M.S. Acupuntura nas desordens reprodutivas (Revisão). PUBVET, Londrina, V. 8, N. 18, Ed. 267, Art. 1776, Setembro, 2014.

pode diminuir doses hormonais e desta forma baixar alguns custos de biotécnicas reprodutivas, motivando esta pesquisa.

Esta revisão tem por objetivo descrever as técnicas terapêuticas de acupuntura associadas às desordens reprodutivas/hormonais.

\section{REVISÃO DE LITERATURA}

\subsection{Ciclo estral}

Os eqüinos apresentam uma reprodução sazonal ou estacional que é baseada em eventos cíclicos que marcam cada estação. Estes eventos cíclicos são resultados dos movimentos de rotação e translação da Terra, que têm ação sobre diversos fenômenos naturais. Baseando-se nestes fenômenos cíclicos foi observado que a tendência natural da maioria dos seres é de adaptar-se às mudanças ambientais o mais eficientemente possível, seguindo os comando dessa organização temporal (SHARP et al., 1993).

Ritmos sazonais no comportamento e na fisiologia são bastante característicos na maioria das espécies que vivem em climas temperados. Estes ritmos são necessários para que haja um sincronismo entre as exigências das funções biológicas e os diferentes períodos do ano, permitindo assim que os indivíduos enfrentem situações de estresse, como: o declínio sazonal de alimentos e disponibilidade de água (YOUNG \& NELSON, 2001).

De acordo com Goeritz et al. (2003), a supressão da reprodução durante o inverno permite que a energia seja utilizada para a termogênese, deixando a reprodução para momentos mais favoráveis. Mecanismos internos se desenvolveram para que os indivíduos antecipem condições ambientais adversas, a fim de inibir a reprodução ou o crescimento. Esta capacidade de previsão foi possível, de acordo com Klein \& Nelson (1999), pela monitorização de fatores extrínsecos, como o comprimento do dia ou fotoperíodo, consumo de alimento e a disponibilidade de água.

Éguas em boa condição corporal e com disponibilidade de alimento, criadas em regiões próximas à Linha do Equador (menor latitude), onde há pouca variação do fotoperíodo, tendem a ciclar durante todo o ano (poliéstricas 
ARAÚJO, A.M.S. Acupuntura nas desordens reprodutivas (Revisão). PUBVET, Londrina, V. 8, N. 18, Ed. 267, Art. 1776, Setembro, 2014.

anuais). Portanto, nestas regiões, o fator nutricional passaria a ser relevante. Se estas mesmas éguas, fossem transferidas para locais de maiores latitudes e, por conseguinte, com variações na duração do número de horas- luz nas diferentes estações do ano, provavelmente, passariam a ter um comportamento reprodutivo sazonal (poliéstricas estacionais).

Durante o inverno, 70 a $80 \%$ das éguas poliéstricas estacionais permanecem em anestro e tornam-se poliéstricas verdadeiras, durante a estação reprodutiva fisiológica ${ }^{3}$. No Rio Grande do Sul, estudando a flutuação anual da taxa ovulatória de éguas abatidas, observou-se que em nenhum mês do ano houve um anestro absoluto, sendo que a taxa mínima registrada foi de $2 \%$ em agosto (TAROUCO et al., 1995). Podemos considerar como período de anestro aquele onde menos de $25 \%$ das éguas ovulam (SHARP, 1980). Baseando-se neste conceito, os mesmos autores (TAROUCO et al., 1995), encontraram um período de anestro nos meses de junho a setembro, com taxas ovulatórias de $17 \%, 6, \%, 2 \%$ e $8 \%$, respectivamente.

O ciclo reprodutivo pode ser definido em duas estações: ovulatória e anovulatória, interligadas por períodos denominados transicionais de primavera e outono. Durante a estação ovulatória, que corresponde aos meses do final da primavera e verão, as éguas ciclam em intervalos regulares. Em pôneis, estas estações são mais rigidamente definidas, enquanto que em outras raças a estação ovulatória é mais longa e um maior número de fêmeas poderá ovular durante todo o ano (WESSON \& GINTHER, 1981)

Os intervalos entre os ciclos estrais e a duração do estro sofrem variações de acordo com a época do ano em que são observados. Normalmente, a duração do estro ovulatório é significativamente menor nos meses de verão em relação aos de outono, inverno e início da primavera. Dados da literatura, relatam uma duração média da fase de estro de 6,5 dias, de diestro de 14,9 e do ciclo estral de 21,7 dias ( GINTHER, 1992). A estação anovulatória geralmente ocorre durante o inverno e início da primavera, com uma duração variável de 40 dias a 8 meses ( HUGHES et al., 1972). Este período compreende os meses do ano nos quais menos de $25 \%$ das éguas 
ARAÚJO, A.M.S. Acupuntura nas desordens reprodutivas (Revisão). PUBVET, Londrina, V. 8, N. 18, Ed. 267, Art. 1776, Setembro, 2014.

ovulam e menos de $10 \%$ permitem a monta do garanhão, sendo que $19,9 \%$ ficam indiferentes a sua presença (SHARP, 1980). As éguas permanecem em anestro com pouca ou nenhuma atividade folicular detectável pela palpação retal, ovários pequenos, conseqüentes da queda estacional da estimulação gonadotrófica, sugerindo produção estrogênica mínima ( GINTHER, 1992).

Com o aumento do fotoperíodo, a atividade antigonadal diminui e a liberação das gonadotrofinas se inicia proporcionalmente. Essa mudança gradual resulta em manifestações "transicionais" caracterizadas pela formação de múltiplos pequenos folículos e a ocorrência de ciclos prolongados, onde o grau de receptividade sexual varia até o estro ser evidente (SHARP, 1980). O período transicional de primavera, no Hemisfério Norte, inicia no final do inverno e culmina com a primeira ovulação do ano que ocorre no final de março e início de abril (HUGHES, 1980). No Hemisfério Sul, foi observado uma fase transicional na atividade ovariana, durante a primavera, quando estros anovulatórios comumente ocorriam (OSBORNE,1966). Um estudo encontrou um nítido aumento de peso nos ovários de julho a agosto, enquanto que a taxa ovulatória ainda estava em declínio, para somente sofrer um acréscimo no mês de setembro ; este período foi caracterizado como o transicional de primavera, onde ocorreu um aumento do número e diâmetro de folículos, refletindo no aumento de peso dos ovários, sem a ocorrência de ovulação (TAROUCO, 1995).

\subsection{Endocrinologia}

Estudos têm demonstrado o envolvimento do hipotálamo e hipófise anterior na estacionalidade reprodutiva de éguas. Em fêmeas ovariectomizadas, mudanças estacionais nas concentrações de FSH e LH influenciadas pelo fotoperíodo, com baixos níveis durante a estação anovulatória e níveis mais altos na ovulatória foram observadas (FREEDMAN et al.,1979a) na estação ovulatória, os ovários exerceram influência positiva sobre a elevação estacional da concentração de LH durante o estro e negativa no diestro. Estes mesmos autores estudaram o 
ARAÚJO, A.M.S. Acupuntura nas desordens reprodutivas (Revisão). PUBVET, Londrina, V. 8, N. 18, Ed. 267, Art. 1776, Setembro, 2014.

padrão estacional das gonadotrofinas em éguas intactas e ovariectomizadas recebendo ou não 16 horas de luz por dia. As éguas que receberam iluminação artificial tiveram os seus níveis séricos de FSH e LH aumentados dois meses mais cedo daquelas sob iluminação natural, indicando que o padrão estacional independe de interações com os hormônios ovarianos (FREEDMAN et al., 1979b). Resultados semelhantes foram encontrados, ao se medir a concentração de LH durante a estação de monta e anestro, em éguas intactas e ovariectomizadas. Observou-se padrões estacionais similares para os dois grupos, revelando que a estacionalidade dos padrões de LH é regulada por fatores ambientais (luz) e que a secreção cíclica de LH, durante a estação ovulatória, é mediada por influências estimulatórias (estrógeno) e inibitórias ( progesterona) provenientes dos ovários ( GARCIA \& GINTHER, 1976).

Em um estudo, em éguas Pônei ovariectomizadas, para localizar as áreas de estoque, distribuição e verificar os efeitos da estação na concentração do $\mathrm{GnRH}$, não foi encontrado efeito significativo da estação na concentração hipotalâmica total de $\mathrm{GnRH}$, mas uma tendência de aumentar nos meses de verão, sendo a sua distribuição significativamente diferente entre as estações $(p<0,05)$ (GARCIA \& GINTHER, 1976).

Efeitos estacionais do eixo hipotalâmico-hipofisiário de 49 éguas mestiças foram pesquisados no Hemisfério Norte, onde se observou uma grande variação no conteúdo hipotalâmico de $\mathrm{GnRH}$, sendo menor em dezembro, durante o inverno, do que em outros meses; Na adenohipófise o conteúdo, o número de receptores para o $\mathrm{GnRH}$ e a concentração de FSH não variaram durante as estações, porém a concentração de LH atingiu níveis máximos em julho, no verão, e mínimos em dezembro(HART et al, 1984). Desta forma os autores concluíram que os fatores responsáveis pelo anestro estacional das éguas, são o conteúdo hipotalâmico de GnRH e a concentração hipofisiária de LH e que além disso, parece que a concentração de LH disponível para a liberação é que atrasa a ovulação durante o período transicional, no início da estação de monta. A estação reprodutiva pode ser alterada experimentalmente 
ARAÚJO, A.M.S. Acupuntura nas desordens reprodutivas (Revisão). PUBVET, Londrina, V. 8, N. 18, Ed. 267, Art. 1776, Setembro, 2014.

pela luz artificial, antecipando o início da estação de monta e o momento da ovulação ( SHARP \& GINTHER, 1975).

$\mathrm{Na}$ Tabela 1, consta a relação de alguns hormônios envolvidos nos eventos reprodutivos de éguas.

2.2.1. Hormônio Liberador das Gonadotrofinas (GnRH): a modulação da atividade reprodutiva pelo fotoperíodo é obtida pela regulação da secreção do $\mathrm{GnRH}$, através dos efeitos inibitórios exercidos pela melatonina liberada pela glândula pineal. O GnRH produzido pelo hipotálamo, atinge a hipófise anterior via sistema hipotálamo-hipófise portal e estimula a síntese e a liberação das gonadotrofinas (FSH/LH), que atingem os ovários via circulação sistêmica.

2.2.2. Hormônio Folículo Estimulante ( FSH): a secreção do FSH durante o ciclo estral é bifásica, com picos de 10 a 12 dias de intervalo. Os picos acontecem ao final do estro, logo após a ovulação e durante a metade final da fase luteal, aproximadamente 10 dias antes da próxima ovulação (BERGFELT \& GINTHER, 1985).

O FSH mantém o contínuo crescimento dos pequenos folículos e estimula a secreção folicular de estrógeno. A sua secreção é mais baixa durante o início do estro, devido ao efeito inibitório da secreção de uma proteína (inibina) pelo folículo de Graff, sendo que esta não atua sobre os níveis de LH (BERGFELT \& GINTHER, 1985). A progesterona tem um efeito de feedback negativo sobre a secreção do LH, mas não sobre o FSH. O aumento dos níveis de FSH durante o final do diestro, é que mantém o estímulo para o desenvolvimento folicular. Assim que o folículo em crescimento atinge o tamanho pré-ovulatório, produz um hormônio protéico, inibina, que inibe a secreção hipofisiária do FSH.

A ação inibitória da inibina sobre o FSH combinado com o efeito estimulatório do estrógeno na secreção do LH, cria o ambiente requerido para a maturação final do folículo de Graff (alta secreção de LH) e previne posterior desenvolvimento de folículos imaturos (baixa secreção de FSH). 
ARAÚJO, A.M.S. Acupuntura nas desordens reprodutivas (Revisão). PUBVET, Londrina, V. 8, N. 18, Ed. 267, Art. 1776, Setembro, 2014.

Tabela 1. Fontes e ações resumidas de alguns hormônios e substâncias de interesse na reprodução (Adaptado de Ginther,1992).

\begin{tabular}{lll}
\hline Hormônio & Fonte & Principal ação \\
\hline Gonadotrofinas & Hipófise anterior & Estimulante luteal: progesterona \\
-LH & Hipófise anterior & Folículo estimulante: estrógenos \\
-FSH & Cálices endometriais & Estimulante luteal: prog. e estróg. \\
-CG & Hipófise anterior & Desenvolv. mamário \\
Prolactina & Hipotálamo & Liberação FSH/LH \\
GnRH & Cérebro & Inibição do LH \\
Opióides & Folículos & Inibição do FSH \\
Inibina & Pineal & Estacionalidade reprodutiva: \\
Melatonina & Untero-placenta & Preparação para o parto/evitar \\
& & contrações durante prenhez \\
Relaxina & Hipotálamo-hipófise & Contrações da musculatura lisa \\
Ocitocina & ant. & \\
Esteróides & & \\
reprodutivos: & & Folículos, \\
-Estrógenos & lúteo(C.L), concepto & Carpo genitália tubular \\
Progestágenos & C.L./ placenta & Mesmas acima \\
-Andrógenos & Folículos, Adrenal & Regulação do FSH \\
ProstaglandinaF2 $\alpha$ & Células endometriais & Luteólise/contrações mus. lisa \\
\hline
\end{tabular}

2.2.3. Hormônio Luteinizante (LH): As concentrações do LH são persistentemente baixas do $5^{\circ}$ ao $16^{\circ}$ dia do ciclo, considerando o dia 0 como o da ovulação. É considerado um agente luteotrófico, ou seja, responsável pelos processos da formação e manutenção do Corpo Lúteo (C.L.). Após a 
ARAÚJO, A.M.S. Acupuntura nas desordens reprodutivas (Revisão). PUBVET, Londrina, V. 8, N. 18, Ed. 267, Art. 1776, Setembro, 2014.

luteólise, ou seja, destruição do C.L. pela $\mathrm{PGF}_{2} \alpha$ liberada pelo útero, os níveis de LH aumentam lentamente, porém progressivamente até atingir o nível máximo 1 a 2 dias após a ovulação e então declinam nos próximos 4 a 5 dias, voltando a valores mínimos durante a fase de diestro (GINTHER, 1985).

Durante o diestro, a concentração do LH é basal, sendo induzida pelo mecanismo de feedback negativo exercido pela progesterona. Após a luteólise, cessado este efeito inibitório, o estrógeno secretado pelos grandes folículos, estimula a secreção do $\mathrm{LH}$, permitindo o desenvolvimento e maturação dos folículos primários e a secreção de mais estrógeno, estabelecendo o mecanismo de feedback positivo. A égua, diferentemente de outras espécies, não apresenta um pico pré-ovulatório de $\mathrm{LH}$, resultante de um rápido aumento de liberação, mas sim uma persistente elevação neste período, que acredita-se estar relacionada com a relativa alta incidência de ovulações duplas nesta espécie, com a segunda ovulação podendo ocorrer com um intervalo de até 4 dias após a primeira. O crescimento pré-ovulatório do folículo e a ovulação podem ocorrer em baixos níveis de LH, como durante o diestro. Isto indica que o papel exato deste hormônio nestes dois processos não é tão imprescindível como em outros animais domésticos (HAFEZ, 2003).

2.4.4. Estrógeno: A secreção folicular de estrógeno atinge o pico 1 ou 2 dias antes da ovulação. Após esta ocorrer, as concentrações deste hormônio, declinam até atingir níveis básicos de diestro, em 2 dias. Similar a outras espécies, um pico de estrógeno de origem folicular, parece iniciar a liberação de LH levando à ovulação. Quando estrógenos conjugados na urina são usados como parâmetro para avaliar a secreção ovariana, sugere que um segundo pico deste hormônio pode ocorrer durante o diestro, devido a presença de muitos folículos de tamanho médio durante esta fase. Ao final do diestro, estes folículos entram em atresia, contribuindo com o decréscimo do estrógeno durante a luteólise. Estudos sugerem que o C.L. pode também ser um menor contribuinte dos níveis de estrógeno durante a fase luteal (DAELS et al., 1991). 
ARAÚJO, A.M.S. Acupuntura nas desordens reprodutivas (Revisão). PUBVET, Londrina, V. 8, N. 18, Ed. 267, Art. 1776, Setembro, 2014.

As concentrações do estrógeno durante o estro, têm mostrado uma boa correlação com atividade ovariana, receptividade sexual e alterações no trato reprodutivo. Na ausência de progesterona $(<1 \mathrm{ng} / \mathrm{ml})$, o estrógeno secretado pelo folículo pré-ovulatório induz a receptividade sexual, relaxamento da cérvice e vulva, estimula secreções do útero, cérvice e vagina, permite a passagem e transporte de sêmen e participa da maturação folicular e ovulação (GHINTER,1992).

2.2.5. Progesterona: Durante o estro, a concentração da progesterona está abaixo de $1 \mathrm{ng} / \mathrm{ml}$. Após a ovulação, os níveis aumentam rapidamente até valores máximos em 6 dias, permanecendo elevado durante a fase luteal ( 6 a $10 \mathrm{ng} / \mathrm{ml}$ ) e declina rapidamente como conseqüência da regressão do corpo lúteo ao redor do $14^{\circ}$ ou $15^{\circ}$ dia do ciclo. A progesterona inibe o comportamento de cio, mantém a cérvice fechada e prepara o útero para manter a prenhez. Também inibe o pico pré-ovulatório de $\mathrm{LH}$, entretanto em contraste com outras espécies, não inibe completamente a foliculogênese e ovulação, podendo, durante a fase luteal, os folículos continuarem a crescer e ovular com níveis elevados de progesterona (HAFEZ, 2000).

A concentração de progesterona durante o estro encontra-se abaixo de $1 \mathrm{ng} / \mathrm{mL}$. Durante a fase de estro encontra-se inferior à $1 \mathrm{ng} / \mathrm{mL}$ (normalmente <0,5ng/Ml). Após 24 a 48 horas da ovulação esta concentração eleva-se progressivamente, atingindo valores máximos de diestro ( 4 a $22 \mathrm{ng} / \mathrm{mL}$ ) entre os dias 5 a 7 pós ovulação. A concentração de P4 se mantém elevada até os dias 13 e 14 do diestro (aproximadamente 3 dias próximo do início do estro) e então regridem rapidamente até atingirem os valores baixos, correspondente ao período de estro (GINTHER, 1992).

Os progestágenos são hormônios que colaboram com a manutenção da prenhez (ALLEN, 1993). No início da gestação eles são em sua maioria de origem ovariana, atingindo um pico aos 25 dias de prenhez e outro em torno de 90 dias (formação dos corpos lúteos secundários). A partir dos 150 dias os 
ARAÚJO, A.M.S. Acupuntura nas desordens reprodutivas (Revisão). PUBVET, Londrina, V. 8, N. 18, Ed. 267, Art. 1776, Setembro, 2014.

progestágenos têm origem na placenta e apresentam aumento significativo nas proximidades do parto (CALDAS et al., 1990).

A administração de progesterona (P4) e progestagéneos na égua é uma prática comum com uma enorme aplicabilidade no controle do ciclo reprodutivo desta espécie. O uso de progesterona inclui: controlo do estro em éguas cíclicas, lactantes e não-lactantes, supressão por tempo prolongado do estro de éguas participantes de eventos hípicos, melhora do tônus uterino, manutenção da gestação e durante o período de transição, antecipação da primeira ovulação da estação, conseqüentemente, suprimindo os longos e erráticos períodos de cio (SILVA et al., 2006).

2.2.6. Prostaglandina: $\mathrm{PGF}_{2 \alpha}$ é considerada como o agente luteolítico primário em éguas. Quando não se apresentam prenhes, a permanência do corpo lúteo é controlada pela liberação da $\mathrm{PGF}_{2}$ a pelas células endometriais entre os dias 13 a 16 após a ovulação. A luteólise medida pelo declínio da concentração de progesterona, ocorre durante, aproximadamente, 40 horas. A primeira liberação desta prostaglandina precede o primeiro declínio dos níveis de progesterona, cerca de 4 horas e é seguida por uma liberação adicional de $\mathrm{PGF}_{2 \alpha}$ durante e após a luteólise (HAFEZ, 2003). Estudos recentes indicam o envolvimento da progesterona, estrógeno e ocitocina na liberação da $\mathrm{PGF}_{2 \alpha}$.

Éguas ovariectomizadas tratadas com progesterona por 14 dias tiveram níveis aumentados desta prostaglandina no lúmem uterino. Acredita-se que uma prolongada exposição uterina à progesterona é necessário para a liberação, provavelmente pela produção de um sistema enzimático de síntese de $\mathrm{PGF}_{2 \alpha}$ ou recrutamento de precursores. Tecido endometrial de éguas em diestro, produziram grande quantidade deste hormônio in vitro na presença de estradiol. Éguas ovariectomizadas durante o final da fase luteal, tratadas com estradiol tiveram maior produção de $\mathrm{PGF}_{2 \alpha}$. $\mathrm{O}$ estrógeno talvez esteja envolvido no processo enzimático da produção desta prostaglandina e parece requerer um pequeno tempo de exposição. Receptores da ocitocina aumentam 
ARAÚJO, A.M.S. Acupuntura nas desordens reprodutivas (Revisão). PUBVET, Londrina, V. 8, N. 18, Ed. 267, Art. 1776, Setembro, 2014.

no endométrio no final da fase luteal; o tecido endometrial responde a produção de $\mathrm{PGF}_{2}$ a na presença de ocitocina in vitro e os níveis circulantes deste hormônio aumentam durante a luteólise (GINTHER, 1992).

\subsection{Dinâmica ovariana:}

O desenvolvimento folicular nas espécies monovulares é subscrito em três fases: primeiramente pela ativação do folículo primordial, em seguida ocorre o recrutamento folicular, posteriormente a seleção de um ou dois folículos dominantes em associação com a atresia dos folículos subordinados (GINTHER \& BERGFELT, 1993). A ativação dos folículos primordiais é necessária para que ocorra a passagem dos folículos quiescentes em uma reserva, para o pool de folículos em crescimento (RUSSE, 1983). O primeiro sinal desta ativação é o retorno da proliferação das células da granulosa, aumento do tamanho do oócito, ocorrendo a passagem do estágio de folículo primordial para o de folículo primário (HISFIELD, 1985).

O desenvolvimento folicular é caracterizado pela diferenciação e proliferação das células da granulosa. A formação de múltiplas camadas de células foliculares cúbicas indica a transformação de folículo primário em secundário. Acompanhando este processo está a formação da zona pelúcida ao redor do oócito. Folículos primários e secundários também são denominados como folículos pré-antrais (HAFEZ, 2000).

Ginther (2000) definiu as ondas foliculares como as ondas maiores e ondas menores. As ondas maiores são caracterizadas pelo desenvolvimento inicial de um grupo de folículos que cresce rapidamente até que apenas um folículo, ou ocasionalmente dois, torna-se dominante sobre os outros. Estas são divididas em ondas primárias e secundárias, de acordo com o momento de sua emergência.

Quando a emergência ocorre durante o cio ou no início do diestro é classificada como onda folicular secundária, a qual origina a um folículo dominante no diestro, o qual pode regredir ou, mais raramente, ovular. A 
ARAÚJO, A.M.S. Acupuntura nas desordens reprodutivas (Revisão). PUBVET, Londrina, V. 8, N. 18, Ed. 267, Art. 1776, Setembro, 2014.

emergência da onda na metade do diestro é denominada de onda folicular primária e produz um folículo dominante que irá ovular durante a fase de estro. As ondas que não apresentam folículos dominantes são classificadas como ondas menores.

Para que ocorra o recrutamento folicular, é necessário que haja uma elevação das concentrações de FSH (FORTUNE, 1994). Em contrapartida, a redução dos níveis de FSH coincide com o desvio nas taxas de crescimento entre o futuro folículo dominante e os folículos subordinados da onda maior. $\mathrm{O}$ desvio também é precedido pelo aumento nas concentrações de $\mathrm{LH}$ (BERGFELT, 1998; GASTAL et al., 2000).

Com a diferenciação entre o folículo dominante e os subordinados, o folículo dominante adquire a capacidade de refratariedade aos níveis decrescentes de FSH, desencadeados pelo mesmo e por supressores do desenvolvimento dos folículos subordinados (FORTUNE, 1994).

Sendo assim, o futuro folículo dominante encontra-se apto a suprimir os níveis de FSH a concentrações inferiores as necessárias ao crescimento dos folículos subordinados e adquire a habilidade de utilizar baixas concentrações de FSH para prosseguir o seu desenvolvimento (GINTHER, 2000). Frente à diminuição dos níveis de FSH circulantes, a aquisição de receptores para LH pelas células da granulosa e as mudanças na vascularização folicular e no sistema IGF parecem ser fundamentais para a continuação do crescimento e diferenciação celular resultando em ovulação (FORTUNE, 2001).

\subsection{Ovulação e formação do corpo lúteo ( C.L.) :}

O processo ovulatório resulta das interações entre o LH e o AMPcíclico, prostaglandinas e enzimas proteolíticas (GHINTER, 1992). A ovulação na égua ocorre na fossa ovulatória que se localiza no bordo côncavo ou ventral do ovário. Um folículo recentemente ovulado é palpado como uma profunda depressão na superfície do ovário. Preenche-se com sangue oriundo da ruptura 
ARAÚJO, A.M.S. Acupuntura nas desordens reprodutivas (Revisão). PUBVET, Londrina, V. 8, N. 18, Ed. 267, Art. 1776, Setembro, 2014.

dos vasos da membrana basal e luteinização das células da granulosa, dentro de 8 a 14 horas, após a ovulação ocorrer ( HUGHES,1972).

$\mathrm{O}$ aumento prolongado do LH, que causa a ovulação, também estimula as células da granulosa a se transformarem em células luteínicas, que invadem e proliferam no coágulo produzido dentro da cavidade folicular, para assim formar o corpo hemorrágico. Um aspecto interessante do desenvolvimento luteal inicial de algumas espécies, é a elevada taxa de crescimento e proliferação celular. Esta última resulta de uma taxa mitótica que se equivale ao rápido crescimento de tumores. Na vaca, por exemplo, o peso do C.L., três dias após a ovulação, é em média de $640 \mathrm{mg}$, passando para 5,1g após 11 dias ( MCCRACKEN, 1999). Este aumento acentuado de massa é devido à hipertrofia das células da granulosa, assim como a divisões mitóticas, posteriormente; uma rápida divisão mitótica e crescimento das células endoteliais e fibroblastos acontecem neste período. Os fatores que regulam a proliferação das células luteínicas pequenas e dos fibroblastos não estão bem caracterizados, porém devem envolver fatores de crescimento fibroblástico hormônio do crescimento (GH) e LH(REDMER, 1996),. O fator de crescimento endotelial vascular (VEGF), um mitógeno específico das células endoteliais, é provavelmente o regulador primário da proliferação destas células a nível de C.L.; este processo ocorre pela necessidade de uma neovascularização da estrutura luteal desenvolvida, sendo que a lâmina capilar corresponde à $22 \%$ do volume total do C.L.( SWANN, 1987). Esta organização celular altamente vascularizada permite uma demanda metabólica intensa, que consome 2 a 6 vezes mais oxigênio por unidade de peso, do que fígado, rins ou coração ( DOUGLAS, 1985).

Na égua, no entanto, que libera o oócito na fossa ovulatória e desenvolve corpos lúteos secundários durante a prenhez, somente as células da granulosa luteinizadas contribuem para a formação do corpo lúteo maduro (MCCRACKEN, 1999). Esta nova estrutura tem uma cor vermelho escura no centro e, nos seus bordos, aparece um tecido luteal pálido e invasor da periferia ao centro (KLEIN \& NELSON, 1999). 
ARAÚJO, A.M.S. Acupuntura nas desordens reprodutivas (Revisão). PUBVET, Londrina, V. 8, N. 18, Ed. 267, Art. 1776, Setembro, 2014.

A medida que o corpo lúteo amadurece, há um aumento progressivo de células luteinizadas, fazendo-o diminuir de tamanho e alterando a sua cor, ficando cada vez mais pálido, assim como a sua superfície vai se tornando irregular. Estudos da morfologia ultra-sônica da glândula luteal evidenciaram que aproximadamente $50 \%$ dos corpos lúteos desenvolvem um coágulo de sangue ao centro e os outros $50 \%$ apresentam um tecido luteal uniforme. Concluíram que o corpo hemorrágico, aparentemente, não é funcionalmente importante porque se desenvolve em apenas $1 / 4$ da estrutura luteal, não alterando o período interovulatório, nem o volume de tecido luteinizado (PIERSON \& GINTHER,1984).

Ao redor do $16^{\circ}$ e $18^{\circ}$ dia do ciclo, o corpo lúteo maduro se transforma em "corpus albicans", resultante da luteólise sofrida em resposta a ação da $\underline{P_{G F}} \underline{\alpha}$ que é liberada pelo endométrio uterino (DOUGLAS et al.,1985). Evidências do envolvimento do útero na indução da luteólise foram relatadas, sendo que éguas submetidas à histerectomia durante a fase luteal, tiveram a atividade dos seus C.Ls. prolongada até 137 dias (GINTHER, 1985).

\subsection{Indução da Ovulação}

Em éguas cíclicas o propósito de se induzir a ovulação é melhorar o manejo reprodutivo e sincronizar a ovulação o mais próximo possível da cobertura, inseminação ou conveniência. Quando a monta natural ou sêmen fresco são utilizados, o intervalo entre a inseminação e a ovulação pode variar entre 0 a 48 horas. Quando do uso de sêmen congelado, uma maior acurácia é necessária, e o intervalo deve ser menor que 24 horas (PALMER, 1993).

A maneira mais apropriada para selecionar o momento de induzir a ovulação consiste na utilização de agentes indutores quando um folículo de $33 \mathrm{~mm}$ é detectado em éguas pôneis e um de $35 \mathrm{~mm}$ em éguas, momento em que o folículo encontra-se responsivo ao LH (PALMER, 1993). Deste modo, após a indução da ovulação, a maioria das éguas irão ovular no período correspondente a 36 e 48 horas da indução, demonstrando uma variação 
ARAÚJO, A.M.S. Acupuntura nas desordens reprodutivas (Revisão). PUBVET, Londrina, V. 8, N. 18, Ed. 267, Art. 1776, Setembro, 2014.

individual acentuada, a qual pode estar relacionada ao diâmetro ovulatório de cada animal (SAMPER, 1997).

A ultra-sonografia é uma ferramenta bastante eficiente na indução da ovulação, não somente pela acurácia proporcionada pela mensuração do diâmetro folicular, como também pela classificação do escore do edema endometrial (variando de 0 a 5, sendo 0 a ausência de edema e 5 o edema máximo). De acordo com Samper (1997) a indução da ovulação com hCG quando o escore de edema encontra-se entre 4 e 5, associado a um folículo entre 35 a $40 \mathrm{~mm}$ de diâmetro apresenta 95\% de eficácia nos dois primeiros ciclos.

\subsubsection{Agentes indutores da Ovulação}

\subsubsection{Gonadotrofina Coriônica humana (hCG)}

O hCG tem sido utilizado por muitos anos para diminuir o período de estro e acelerar a ovulação, sua eficiência é amplamente demonstrada na indução da ovulação quando um folículo pré-ovulatório é detectado de fato, a administração do hCG em éguas com um folículo pré-ovulatório de pelo menos $35 \mathrm{~mm}$ é capaz de induzir a ovulação em até 48 horas em $80 \%$ dos casos (BERGFELT, 2000). Portanto, a utilização de hCG aumenta a probabilidade de um ciclo ovulatório estar associado a uma única cobertura, viabilizando o planejamento do acasalamento. Objetivando inseminar cada vez mais éguas uma única vez o mais próximo possível da ovulação (VERONESI et al., 2003). A administração do hCG em éguas em cio contendo mais de um folículo préovulatório tem ampliado a possibilidade de ocorrer dupla ovulação (WOODS \& GINTHER, 1983).

Uma única dose de hCG é utilizada para induzir a ovulação. Aparentemente não existe um padrão ou nível de dose, variando entre 1.000 U.I. a 6.000 U.I. ou mais, sendo que a maioria das doses utilizadas é entre 1.500 a 3.000 U.I.. O momento da administração do hCG normalmente é 
ARAÚJO, A.M.S. Acupuntura nas desordens reprodutivas (Revisão). PUBVET, Londrina, V. 8, N. 18, Ed. 267, Art. 1776, Setembro, 2014.

ditado pela associação de alguns fatores, dentre eles: a) período do ano; b) comportamento de estro; c) ecotextura uterina, tônus uterino e cervical; d) ecotextura da parede do folículo pré-ovulatório; f) diâmetro e formato do maior folículo. De todos os fatores citados, a administração do hCG é realizada quando um folículo atinge $35 \mathrm{~mm}$ de diâmetro durante a fase folicular (BERGFELT, 2000).

Apesar de ser um agente indutor de ovulação largamente utilizado, o hCG apresenta a inconveniência de induzir a formação de anticorpo após algumas injeções sucessivas (DUCHAMP et al., 1987). Demonstraram ainda que a formação de anticorpos se inicia após 2 a 5 injeções de hCG, mas falhou em demonstrar refratariedade, a despeito das altas taxas de anticorpos, discordando de Sullivan et al., (1973), os quais observaram a refratariedade após a terceira administração do hCG.

A utilização de uma dose de dexametasona $(20 \mathrm{mg}$ de fofato de sódio de dexametasona $+40 \mathrm{mg}$ fenilpropionato de dexametasona) simultaneamente ao hCG, objetivando a inibição da formação de anticorpos não foi eficiente de acordo com Duchamp et al. (1987), entretanto estes mesmos autores admitem a possibilidade de uma única dose não ser eficiente na inibição do sistema imunológico.

McCue et al. (2004) também observaram que repetidas doses de hCG durante a estação de monta está relacionada com a menor eficácia na indução da ovulação, sugerindo a utilização deste agente no máximo duas vezes por estação de monta. Os mesmos autores também observaram uma redução no percentual ovulação entre 24 e 48 horas após a indução nas éguas com idade avançada (acima de 15 anos).

\subsubsection{Hormônio Liberador de Gonadotrofina (GnRH)}

Muitos estudos tem avaliado o uso do GnRH e seus análogos no controle do ciclo estral de éguas. A administração do GnRH sintético durante o estro estimula a liberação de LH e reduz a duração do estro (IRVINE et al., 1975). O 
ARAÚJO, A.M.S. Acupuntura nas desordens reprodutivas (Revisão). PUBVET, Londrina, V. 8, N. 18, Ed. 267, Art. 1776, Setembro, 2014.

desenvolvimento de agonistas e análogos de GnRH aumentou a meia vida deste hormônio através de modificações estruturais no GnRH natural, o que permitiu o aumento nos níveis de LH por 12 a 24 horas após a administração dos mesmos (BERGFELT, 2000).

A maioria dos análogos são produzidos pela substituição e/ou remoção dos aminoácidos da molécula natural de GnRH. A substituição da glicina na posição 6 por D-alanina, triptofano ou serina confere uma maior estabilidade estrutural e metabólica, aumentando a meia-vida e a açãodo análogo (Monahan et al., 1973). Um dos agonistas do GnRH utilizados na espécie eqüina é a burserelina, a qual foi bem sucedida quando administrada duas vezes ao dia após a detecção de um folículo de 35mm (SQUIRES et al., 1981).

A deslorelina é um análogo do $\mathrm{GnRH}$ produzido pela substituição da glicina na posição 6 pelo triptofano, retirando a glicina da posição $10 \mathrm{e}$ adicinando uma amida na prolina da posição 9 (6-D-triptofano-9-(N-etil-Lprolinamida)-10-Desglicinamida LH-RH). Encontra-se disponível na forma comercial de Ovuplant_, um implante de curta duração que libera 2,2mg a cada 2 a 3 dias. Este implante de deslorelina tem-se demonstrado eficiente em aumentar as concentrações de LH e induzir a ovulação em éguas cíclicas (SQUIRES et al., 1994).

Três estudos compararam o Ovuplant com o hCG e obtiveram um intervalo entre tratamento e ovulação, respectivamente, de 1.98 a 1.88 dias (MCKINNON et al., 1993), 46,9 a 43 horas (MEINERt el al., 1993) e 2, 2 a 2,2 dias (VANDERWALL et al., 2001). Melo et al. (2005) compararam o uso de deslorelina (1 mg/IM) com o extrato de pituitária eqüina (EPE) (10mg/IV) e constataram que ambos os agentes foram eficientes na indução da ovulação, sendo que o período ovulatório após a administração da deslorelina e do EPE, foram respectivamente: 38, 9 e 34, 7 horas. Mumford et al. (1995) compararam o efeito do número de implantes subcutâneos (1, 3 ou 5 implantes de 2,2mg de deslorelina) injetados após a detecção de um folículo de $35 \mathrm{~mm}$, repetindo o mesmo protocolo por três vezes com a mesma éguas. Estes autores não observaram diferenças entre as doses utilizadas, bem como 
ARAÚJO, A.M.S. Acupuntura nas desordens reprodutivas (Revisão). PUBVET, Londrina, V. 8, N. 18, Ed. 267, Art. 1776, Setembro, 2014.

não foi observado nenhum efeito deletério na administração da deslorelina durante três ciclos consecutivos. Com relação às taxas de ovulação, quando da injeção de um implante de deslorelina, $83,3 \%$ das éguas ovularam num intervalo de até 48 horas da injeção e para 3 ou 5 implantes, foram de 73,3 e 85,7 , respectivamente.

Samper et al. (2002) compararam o uso de hCG (Chorulon, Intervet) com a deslorelina (Ovuplant - Pharmacia and UpJohn Co), nas doses de 2500 UI e 2,2mg respectivamente. As éguas foram distribuídas aleatoriamente nos dois grupos e a ovulação foi induzida quando as éguas apresentaram edema uterino com escore entre 2 a 4 . O intervalo entre a indução e a ovulação foi maior para as éguas que receberam hCG ( 28 a 96 horas) em relação às que receberam a deslorelina (36 a 42 horas). Com isso pode-se concluir a eficiência da deslorelina em reduzir o número de coberturas, bem como o número de visitas do veterinário para realizar o controle folicular, sendo de grande auxílio para os programas de transferência de embrião e inseminação artificial, especialmente para sêmen refrigerado e congelado.

\subsubsection{Down Regulation}

Os receptores de GnRH quando estimulados continuadamente e uma eventual redução no número de receptores são fatores que levam a refratariedade deste hormônio, acarretando na supressão das gonadotrofinas endógenas. A falta de gonadotrofinas inibe a função reprodutiva, incluindo o desenvolvimento folicular, a ovulação e a fase luteal (FRASER, 1981). A redução do número de gonadotrofos tem sido denominada de "down regulation", o que tem sido um eficiente método contraceptivo (IRVINE, 1983). Dentre as possíveis causas para a redução nas concentrações de $\mathrm{LH}$ e FSH encontra-se a redução na secreção endógena de GnRH pelo hipotálamo (CROWDER et al., 1986), desensibilização da pituitária ao estímulo do GnRH e/ou a depleção de LH e FSH pela pituitária. 
ARAÚJO, A.M.S. Acupuntura nas desordens reprodutivas (Revisão). PUBVET, Londrina, V. 8, N. 18, Ed. 267, Art. 1776, Setembro, 2014.

A prolongada supressão das gonadotrofinas pelo down regulation seguido do estímulo elevado e constante pelo GnRH geralmente é ocasionado pela redução da sensibilidade dos gonadotrofos (Sandow, 1983), mais que pela estimulação do GnRH (ZILBERSTEIN et al., 1983).

De um modo geral, acredita-se que as éguas sejam relativamente refratárias ao down regulation ocasionado pelos análogos do $\mathrm{GnRH}$ (FITZGERALD et al., 1993). Em equinos, o tratamento com análogos de GnRH por período prolongado (28 dias) e altas doses $(1,3 \mathrm{mg} / \mathrm{kg} / \mathrm{dia})$ reduziu a concentração de LH semelhante as outras espécies (FITZGERALD et al.,1990). O tratamento de éguas com altas doses de análogo de $\mathrm{GnRH}$ (10mg/dia) resultou em uma supressão reversiva da atividade ovariana causando uma redução na duração do ciclo estral (PALMER \& QUELLIER, 1988).

\subsubsection{Extrato de Pituitária Eqüina (EPE)}

O extrato de pituitária eqüina tem sido usado em diversos protocolos de superovulação em éguas (ALVARENGA et al, 1999 e 2001). Duchamp et al. (1987) demonstraram que uma única administração de $25 \mathrm{mg}$ de $E P E$, na presença de um folículo de $35 \mathrm{~mm}$ de diâmetro, induziu a ovulação em $75 \%$ das éguas no período entre 24 e 48 horas.

Medeiros et al. (2005) compararam o uso do EPE na concetração de 10 e $5 \mathrm{mg}$ intravenoso e constataram que ambas as doses foram eficientes em induzir a ovulação em um período de 48 horas do momento da ovulação,

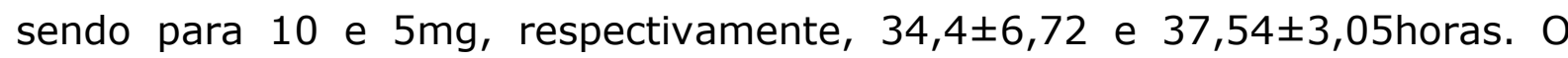
extrato de pituitária eqüina ao contrário do hCG não induz a formação de anticorpos. Entretanto deve-se levar em consideração a heterogeneidade das amostras de EPE (PALMER, 1993).

Além da eficiência do EPE na indução de ovulação em éguas, outra vantagem é o estreito do intervalo entre a indução e a ovulação, o que favorece o uso de sêmen congelado nesta espécie, por reduzir o número de inseminações sem o comprometimento da fertilidade (MELO, 2005). 
ARAÚJO, A.M.S. Acupuntura nas desordens reprodutivas (Revisão). PUBVET, Londrina, V. 8, N. 18, Ed. 267, Art. 1776, Setembro, 2014.

\subsection{Transferência de embrião}

A transferência de embriões é uma biotécnica baseada no princípio da multiplicação da progênie de fêmeas consideradas superiores dentro de um rebanho. Fundamenta-se na obtenção de embriões de uma fêmea doadora para em seguida transferí-los para fêmeas receptoras, com a finalidade de completar o período de gestação. Avaliando a importância do melhoramento genético do rebanho esta técnica é a mais acessível e proporciona o melhor aproveitamento de uma doadora, multiplicando seu material genético (GINTHER, 1992).

A transferência de embriões (TE) é uma importante ferramenta que visa acelerar o melhoramento genético, conferindo maior precisão e rapidez no processo de seleção animal. O primeiro relato envolvendo TE em eqüinos em 1972, embora incrementos na pesquisa só acorresse uma década depois. No Brasil, a TE vem sendo realizada desde a década de 80, ocupando, hoje, lugar de destaque no mundo, junto Estados Unidos e Argentina (CARMO \& ALVARENGA, 2003).

\subsection{Taxa de Recuperação}

As taxas de coleta de embriões têm variado de 40 a $80 \%$ (RIERA \& McDONOUGH, 1993; FLEURY, 1998). Estão em torno de 50\% para éguas que apresentam uma única ovulação (SQUIRES, 1999). Vários fatores podem interferir nas taxas de coleta e de certa forma explicar a grande amplitude de resultados observados. Dentre eles podem-se citar: idade da égua (SQUIRES et al., 1999), fertilidade da doadora (KATILA et al., 1989; SQUIRES et al., 1999), dia de coleta (MCKINNON \& SQUIRES, 1988a), multiplicidade de ovulações (SQUIRES et al., 1989), reprodutor (PASHEN et al., 1993), sêmen (SQUIRES et al., 1999) e época da estação de monta (PASHEN et al., 1993). 
ARAÚJO, A.M.S. Acupuntura nas desordens reprodutivas (Revisão). PUBVET, Londrina, V. 8, N. 18, Ed. 267, Art. 1776, Setembro, 2014.

\subsection{Gestação}

O nível plasmático considerado satisfatório por Sharp (2000) para manutenção da gestação é de $4 \mathrm{ng} / \mathrm{mL}$. Esse nível foi consistentemente atingido com doses de $200 \mathrm{mg} / \mathrm{dia}$, confirmando que níveis séricos de progesterona inferiores a $1 \mathrm{ng} / \mathrm{mL}$ caracterizam o período do estro. Bergfelt \& Ginther (1996) verificaram em éguas e pôneis que a concentração de progesterona $(\mathrm{ng} / \mathrm{mL})$ foi próxima de zero no dia da ovulação e atingiu aproximadamente 3,0 no D2 e 11,0 no D7 em ambos os grupos de fêmeas. No D4, a concentração de progesterona foi menor nas éguas (em torno de 7,0 $\mathrm{ng} / \mathrm{mL}$ ) que nos pôneis (em torno de 9,0 ng/mL). Souza et al. (1999), trabalhando com potras da raça Brasileiro de Hipismo, encontraram concentrações médias de progesterona plasmática de $5,6 \mathrm{ng} / \mathrm{mL}$ no 40 dia pós-ovulação. Essas concentrações permaneceram elevadas até o 14 o dia, quando retornaram a valores basais. Trabalhando com radioimunoensaio, HOLTAN et al. (1975) e NETT et al. (1976) não encontraram, respectivamente, diferenças nas concentrações de progesterona, no $8^{\circ}$. e $12^{\circ}$. dia após a ovulação, entre éguas gestantes e vazias.

A perda embrionária tem sido relacionada à baixa concentração de progesterona durante prenhez precoce (Douglas et al. 1985; Ginther, 1985). Valor inferior a $2,5 \mathrm{ng} / \mathrm{mL}$ no dia 12 foi usado como valor crítico para identificação de éguas com "disfunção luteal". Hinrichs \& Kenney (1987) demonstraram que éguas ovariectomizadas tratadas com $300 \mathrm{mg} / \mathrm{dia}$ de progesterona em óleo mantiveram a gestação após a transferência de embrião. Estes pesquisadores utilizaram os progestágenos por um período superior a 100 dias até que a placenta passou a suprir a necessidade fisiológica de progesterona necessária para manutenção da prenhez. Segundo Castro (2005) a P4 elevada na fase estrogênica e baixa na fase progesterônica pode determinar respectivamente falhas na ovulação ou ambiente uterino inadequado para a manutenção de gestação, sendo causas de infertilidade em éguas. 
ARAÚJO, A.M.S. Acupuntura nas desordens reprodutivas (Revisão). PUBVET, Londrina, V. 8, N. 18, Ed. 267, Art. 1776, Setembro, 2014.

Cada vez mais tem se intensificado o estudo da relação entre a concentração de progesterona sérica e a taxa de prenhez. Fêmeas que falham na concepção apresentam menores níveis de progesterona do que aquelas que concebem. O desenvolvimento embrionário e a habilidade do concepto em secretar Interferon-tau, tem sido relacionado com a concentração de progesterona sérica. No entanto, os resultados são inconsistentes quanto ao uso de progesterona exógena sobre o efeito na taxa de prenhez.

\subsection{Acupuntura}

A acupuntura é um dos métodos mais antigos de tratamento médico. A prática da acupuntura veterinária é provavelmente tão antiga quanto a humana. Na verdade, o campo da acupuntura veterinária começou com o tratamento de cavalos, por causa de sua importância numa economia baseada em guerras e agricultura. O primeiro registro histórico de tratamento de animais com acupuntura na China data do século XI a.C., no Li-Jing, o Cânon dos rituais, onde se descreveu como se estimulavam os cavalos, com agulhas, como preparativos para as batalhas e, a literatura do século $X$ a.C., descreveu a técnica a ser utilizada para tratamento da insolação em cavalos (XINNONG, 1999).

O termo acupuntura provém das palavras em latim acus, significando "agulha", e pungere, significando "perfurar". Em resumo, é a técnica de perfurar a pele com agulhas finas em locais pré-determinados, chamados pontos de acupuntura, para prevenir ou tratar doenças. A estimulação desses pontos por intermédio de métodos modernos inclui a inserção de agulhas, injeção, ultra-som, laser, ultravioleta, indução magnética e estimulação elétrica (MACCIOCIA, 1996). 
ARAÚJO, A.M.S. Acupuntura nas desordens reprodutivas (Revisão). PUBVET, Londrina, V. 8, N. 18, Ed. 267, Art. 1776, Setembro, 2014.

\subsubsection{Teoria Yin e Yang}

É uma estrutura conceitual que foi usada para observação e análise do mundo material na China antiga. O conceito de Yin e Yang é provavelmente o mais importante e distintivo da teoria da medicina chinesa. Pode-se dizer que toda a fisiologia médica chinesa, patologia e tratamento podem, eventualmente, ser reduzidos ao Yin e Yang. Estes representam qualidades opostas, mas também complementares, na qual cada coisa poderia existir por si mesma ou pelo seu oposto. O Yang está associado a itens e conceitos relacionados ao brilho, à luz, ao calor e ao movimento, enquanto o Yin ao escuro, ao frio, à lentidão (MACCIOCIA, 1996).

Desde os primeiros tempos, os dois pólos arquetípicos da natureza foram representados não apenas pelo claro e escuro, mas, igualmente pelo masculino e feminino, pelo inflexível e dócil, pelo acima e abaixo. Yang, o forte, o masculino, o poder criador, era associado ao céu, enquanto o Yin, o escuro, o receptivo, o feminino, o material, era representado pela terra. 0 céu está acima e está cheio de movimento. A terra está abaixo e em repouso. Dessa forma, Yang passou a simbolizar o movimento e Yin o repouso. No reino do pensamento, Yin é a mente intuitiva, feminina e complexa, ao passo que Yang é o intelecto masculino, racional e claro. Yin é a tranqüilidade contemplativa do sábio, Yang a vigorosa ação criativa do rei (LIN, 1998).

A relação interdependente de Yin e Yang significa que cada um dos aspectos é a condição da existência do outro e nenhum deles pode existir isoladamente. Por exemplo, sem o dia não existiria a noite. Portanto, concluise que Yin e Yang estão em oposição e interdependência. Estes dependem um do outro para a própria existência, co-existindo numa entidade única. $\mathrm{O}$ movimento e a mudança de algo são decorrentes não somente da oposição e do conflito entre Yin e Yang, mas também da sua relação de interdependência e de suporte mútuo (SAN, 1996). 
ARAÚJO, A.M.S. Acupuntura nas desordens reprodutivas (Revisão). PUBVET, Londrina, V. 8, N. 18, Ed. 267, Art. 1776, Setembro, 2014.

\subsubsection{Substâncias fundamentais}

A MTC baseou-se na observação do organismo e da sua interação com o meio ambiente. $O$ interesse em observar os ciclos da natureza e o comportamento das funções orgânicas em relação a estes ciclos, levou a conhecimentos profundos de fisiologia e sua relação com o meio ambiente. Apesar de já terem conhecimento de anatomia e de realizarem cirurgias a cerca de 100 anos d.C., estes conhecimentos não são muito levados em consideração. Na medicina chinesa a função sempre foi mais valorizada e os chineses nunca se preocuparam com descrições anatômicas minuciosas, por que acreditavam ser pouco fidedigno o estudo do cadáver, que já perdeu sua mais importante característica: a função (ROSS, 1985), como pode ser observado na expressão:

"O intestino delgado recebe os alimentos mortos e dá a cada um sua vida própria."

Este conceito de digestão, contido no Nei Jing há milênios, ilustrou o quanto já eram avançadas as noções de fisiologia. Os chineses descreveram a circulação sangüínea cerca de dois mil anos antes de William Harvey (1628) em seu famoso livro "Sobre o Movimento do Coração e Sangue de Animais".

É possível observar a riqueza dos conhecimentos tradicionais e perceber várias similaridades com a fisiologia ocidental. Os constituintes fisiológicos básicos do corpo são cinco, segundo a tradição chinesa: Qi, que pode ser traduzido como função ou energia vital, Xue (sangue), Jin-Ye (líquidos corporais), Jing (essência) e Shen (mente ou espírito) (KLIDE, 1977).

\subsubsection{Teoria dos meridianos}

Foram considerados como meridianos os canais distribuídos por todo o corpo por onde circula a energia (Qi) e o Sangue (Xue). Estes meridianos 
ARAÚJO, A.M.S. Acupuntura nas desordens reprodutivas (Revisão). PUBVET, Londrina, V. 8, N. 18, Ed. 267, Art. 1776, Setembro, 2014.

possuem pontos específicos, chamados pontos acupunturais, nos quais é possível intervir com o fluxo energético de Qi (ANTONIO, 1977). O sistema de meridianos unifica todas as partes do organismo, conectando os órgãos internos com o corpo externo e mantendo a harmonia e o equilíbrio. Este, composto por 12 pares de canais regulares, cada um correspondendo a um dos 12 Zang-Fu. Dentre os oito meridianos chamados extraordinários, apenas dois são considerados importantes, pois eles possuem pontos que não se situam nos outros meridianos. Estes dois canais, o Du Mai (vaso governador) e o Ren Mai (vaso da concepção), juntamente com os 12 meridianos principais são usados na acupuntura contemporânea (SCHOEN, 2006).

\subsubsection{Zang-Fu (Órgãos e Vísceras)}

Os Zang-fu recebem o mesmo nome de órgãos anatômicos na ciência ocidental. Entretanto, se comportam como eixos funcionais multiorgânicos, com diversas atividades e correlações que transcendem as suas funções fisiológicas e localização anatômica. A medicina chinesa definiu estas relações a partir de observações minuciosas das reações fisiológicas e fisiopatológicas do organismo chegando ao ponto de correlacionar aos Zang-fu com funções mentais e emoções específicas (SCHOEN, 2006).

A MTC estabeleceu o estudo da anatomia e da fisiologia dos Órgãos Zang e Vísceras Fu para explicar o funcionamento e as modificações fisiológicas do organismo (BASTOS, 1993).

\subsubsection{Pontos de acupuntura}

Cada ponto de acupuntura possui uma função definida e específica, baseada na resposta do corpo. São sítios localizados na superfície do corpo e é por meio destes pontos que se consegue regular a energia corporal (SUMANO \& LÓPEZ, 1990). 
ARAÚJO, A.M.S. Acupuntura nas desordens reprodutivas (Revisão). PUBVET, Londrina, V. 8, N. 18, Ed. 267, Art. 1776, Setembro, 2014.

Na MTC cada ponto acupuntural é identificado por nomes. No ocidente há uma classificação diferente, no qual os pontos são identificados através de números acompanhados da sigla correspondente a cada meridiano (MANN, 1982).

A teoria clássica reconhece cerca de 365 pontos localizados nos meridianos regulares. Histologicamente a área correspondente a estes pontos apresenta uma estrutura própria com um adelgaçamento do epitélio devido a uma modificação de fibras colágenas da derme, uma rede espiral vascular rodeado por uma densa rede de fibras nervosas amielínicas do tipo colinérgico, e que apresenta uma baixa resistência elétrica em comparação ao resto do corpo. Estes pontos acupunturais possuem uma área medida de $1 \mathrm{~mm}^{2}$, com base nestas características histológicas. São também perceptíveis pelo fenômeno da luminosidade biológica pelo método de fotografia de Kirlan, fotografias de alta freqüência, desenvolvidas por um pesquisador russo em 1939, em que através da fotografia se observou trajetos roxo-amarelados, que foram correlacionados aos pontos Yang e os trajetos azuis foram correlacionados aos pontos Yin (SUMANO \& LÒPEZ, 1990).

Os reflexos da excitação produzidos nos pontos acupunturais se transmitem pelos troncos nervosos até o sistema nervoso central, ao invés de haver uma resposta motriz há uma reação do sistema nervoso autônomo que tende a normalizar os órgãos correspondentes (SUMANO \& LÒPEZ, 1990). Porém, Lin et al. (2008) afirmaram que os estudos fisiológicos das bases do tratamento por acupuntura na medicina ocidental ainda estão nas suas etapas iniciais e pouco se sabe sobre os intrincados processos que coordenam a atividade reprodutiva, e principalmente como estes são modificados e equilibrados pelos estímulos dos acupontos.

De acordo com Kendall (1999), os mecanismos pelos quais a acupuntura consegue desencadear seus efeitos restaurativos envolvem uma série de interações locais e sistêmicas das quais participam o sistema nervoso, endócrino e vascular. No sistema nervoso central a ação parece envolver a 
ARAÚJO, A.M.S. Acupuntura nas desordens reprodutivas (Revisão). PUBVET, Londrina, V. 8, N. 18, Ed. 267, Art. 1776, Setembro, 2014.

modulação da síntese e secreção de serotonina embora outros transmissores também participem.

A estimulação por agulhas em certos pontos, como o Bai Hui e VG2, estão historicamente associados com a reprodução e sabidamente altera os níveis plasmáticos de hormônio luteinizante (LH), hormônio folículo estimulante (FSH), estradiol, progesterona e testosterona (LIN, 1998). Uma possível explicação destes fenômenos endócrinos envolveria um mecanismo mediado pela endorfina. Esta é capaz de inibir e a naloxone que inibe o pico de $\mathbf{L H}$ (MALVEN, 1984). Muitos estudos têm demonstrado que a acupuntura pode aumentar o nível de endorfina no cérebro, na medula espinhal e no sangue (BOSSUT, 1986; MALVEN, 1987). Desta forma, Lin et al. (2008) afirmaram que a diminuição do LH pode ser mediada pela endorfina e após o período de depressão, a hipófise se torne mais responsiva ao hormônio gonadotrófico (GnRH). Outra possibilidade, de acordo com Batista et al. (2004), seria a acupuntura agindo diretamente no controle parácrino e autócrino da esteróidigênese pela estimulação da produção de secreção de epinefrina e fatores de crescimento locais.

\subsection{Métodos de tratamento}

Os pontos podem ser estimulados de diversas maneiras, dentre elas: a fixação de sementes de mostarda em pontos auriculares, a simples inserção de agulhas, a eletroacupuntura, a moxabustão, a aquapuntura e a utilização de ventosas. Para estimulações mais demoradas de até 15 dias, pode ser realizada a sutura subcutânea na região do ponto com fios categute ou sintético absorvível 2-0 e para tratamentos permanentes, pode-se fixar esferas de metais nobres em pontos específicos (LIN et al., 2008).

Estímulos provocados pela agulha em diferentes receptores nervosos, segundo Siterman et al. (2000), levaram a múltiplos efeitos, uma vez que o sistema nervoso dá uma resposta específica conforme a via de condução do estímulo. A técnica de manipulação da agulha quanto à intensidade, no sentido 
ARAÚJO, A.M.S. Acupuntura nas desordens reprodutivas (Revisão). PUBVET, Londrina, V. 8, N. 18, Ed. 267, Art. 1776, Setembro, 2014.

de rotação (horário ou anti-horário), freqüência, inclinação e, profundidade, torna-se muito importante, pois diferentes neurotransmissores são liberados, excitando ou inibindo, resultando em interpretações cerebrais distintas e diferentes respostas.

\subsection{Métodos de localização dos pontos de acupuntura}

A localização do ponto deve ser precisa, uma vez que afeta diretamente o resultado do tratamento. O ponto, em geral, localiza-se numa depressão da pele, identificável à palpação, daí a concepção oriental de "buraco". Desta forma, para melhor identificação deve-se levar em conta a dor local, consistência e coloração da pele (XINNONG, 1999).

Em geral os acupontos são encontrados principalmente em depressões ao longo de fissuras entre músculos, tendões e ossos. E se comunicam com os Zang-fu pelo sistema de meridianos e estes são percebidos como uma complexa rede de canais principais e seus colaterais (SCHOEN, 2006). Porém, segundo Macciocia (1996) pode-se encontrar pontos em locais onde não haja acidentes anatômicos que sirva de referência. Por isso, foi desenvolvido um sistema de distâncias ("CUN" em chinês). Onde 1cun equivale à distância entre as pregas interfalangeanas do indivíduo em tratamento, este sistema é proporcional e particular a cada paciente (Figura 1). 
ARAÚJO, A.M.S. Acupuntura nas desordens reprodutivas (Revisão). PUBVET, Londrina, V. 8, N. 18, Ed. 267, Art. 1776, Setembro, 2014.

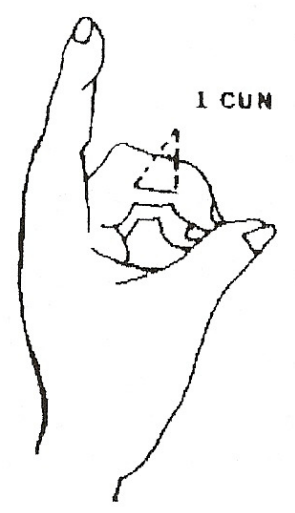

Figura 1: Sistema de distância segundo a Medicina Tradicional Chinesa (Cun)

\subsection{Reprodução e Medicina Tradicional Chinesa}

De acordo com a MTC as funções reprodutivas dependem de um complexo de funções cooperativas que envolvem os órgãos internos, o Qi-Xue, os meridianos, especificamente os órgãos do aparelho reprodutivo. Os órgãos internos e seus meridianos, principalmente o rim, o baço-pâncreas, o fígado e o coração abastecem o útero, o feto, a placenta, os ovários, as glândulas mamárias em lactação, os testículos e o pênis com Qi e Xue, que por sua vez, é o alimento essencial a todas as atividades orgânicas necessárias à manutenção e perpetuação da vida (LIN et al., 2001).

Aso et al. (1976) já sugeriam que quando realizada a estimulação adequadamente em pontos de acupuntura, pode promover um efeito na função endócrina da fêmea. Quando fizeram a dosagem sérica de LH e FSH em mulheres, sem estímulo externo, obtiveram níveis normais para o período estral que se encontravam, porém quando fizeram eletroestimulação em pontos específicos, os níveis de LH e FSH novamente dosados apresentaram uma elevação.

De maneira simplificada, as deficiências de Yin ou Yang de determinados órgãos e/ou funções, que resultassem no abastecimento irregular ou insuficiente de Qi e Xue do sistema reprodutor, seriam as causas principais das lesões ou mau funcionamento destes (KENDALL, 1999). 
ARAÚJO, A.M.S. Acupuntura nas desordens reprodutivas (Revisão). PUBVET, Londrina, V. 8, N. 18, Ed. 267, Art. 1776, Setembro, 2014.

Vários estudos utilizando a acupuntura num sítio associado a função ovariana, conhecida como espaço lombo-sacral (LSS), constatando que éguas que recebiam a dose convencional de prostaglandina e éguas tratadas com baixas doses deste mesmo hormônio administrada no espaço lombo-sacro, apresentavam concentrações progesterona indicativa de luteólise (Alvarenga et al., 1997, 1998; Luna et al., 1999).

\section{REFERÊNCIAS BIBLIOGRÁFICAS}

ALLEN, W.R. Progesterone and the pregnant mare: unanswered chestnuts. Equine Veterinary Journal, v. 25, p. 90-91,1993.

ALMEIDA, H. B.; VIANA, W. G.; ARRUDA, R. P.; OLIVEIRA, C. A. Sincronização de estro e dinâmica folicular de éguas Crioulas submetidas a tratamentos com norgestomet, acetato de melengestrol e altrenogest Brazilian Journal Veterinary Res. animal Science., São Paulo, v. 38, n. 6 , p. $267-272,2001$.

ALVARENGA, MA, JPC FERREIRA, C. MEIRA, LUNA SPL, PJ BURNS.. A indução de luteólise em éguas utilizando uma micro-dose de Sub prostaglandinas $F 2$ no espaço sacro lombar. Proc. Equine Nutrition Physiology. Societ. p. 270, 1997.

ALVARENGA, MA, JPC FERREIRA, C. MEIRA, LUNA SPL, PJ BURNS, A indução de luteólise em éguas utilizando uma micro-dose de prostaglandina no sacro lumbarspace. Equine Veterinary Science. v.18, n.3, p.167, 1998.

ALVARENGA, M.A.; MCCUE, P.; SQUIRES, E.L.; NEVES NETO, J.R. Improvement of ovarian superstimulatory. Response and embryo production in mares treated with equine pituitary extract twice daily. Theriogenology, v.56, p.879-887, 2001.

ALVARENGA, M.A.; MCCUE, P.; SQUIRES, E.L.; NEVES NETO, J.R. Improvement of ovarian superestimulation in mares treated with EPE twice daily. Arquivos da Faculdade de Veterinária. s. 27, p. 197, 1999.

ANTONIO, F.F. Tratado General de Acupuntura China: Fisiopatologia Diagnóstico Y Tratamiento. Buenos Aires: Ediestrones Científico-Técnicos Americanas, 427p, 1977.

ARRUDA, R. P.; MADUREIRA, E. H.; MIZUTA, K.; GUSMÕES, P. P.; VON ZUBEN, C.; VISINTIN, J. A.; RODRIGUES, P. H. M. Sincronização do estro em fêmeas bovinas com o uso de Acetato de Melengestrol (MGA)-prostaglandina F2 $\square \square$ e CIDR-B. Revista Brasileira de Reprodução Animal. v. 21, n. 2, p. 97-99, 1997.

ASO, T.; MOTOHASHI, T.; MURATA, M.; NISHIMURA, T.; KAKIZAKI, K.; KIMURA, S. The American Journal of Chinese Medicine. v. 4, n. 4, p. $391-401,1976$. 
BATISTA, G.T.C. Acupuntura: tratamento e procedimentos na auditoria médica. Goiânia: da Universidade Gama Filho em parceria com a Universidade UNIMED, 2004, 48p. Dissertação (especialização "latu-sensu"), UGF/UNIMED, 2004.

BASTOS, R.S.R.C. Tratado de eletroacupuntura: Perspectivas Científicas, teoria e Prática. RJ. Numen editora, 492p, 1993.

BAKER, C.B. \& KENNEY, R.M.. Systematic Approach to the Diagnosis of the Infertile or Subfertile Mare. In: MORROW (ed) Current Therapy in Teriogenology . W.B. Saunders Co. Phyladelphia. p. 721-736, 1980.

BERGEFELT, D.R. Estrous synchronization. mare. In: Equine Breeding Management and Artificial Insemination. Philadelphia: Saunders, p.195-228, 2000.

BERGFELT, D.R. \& GINTHER, O . J.,. Delayed follicular development and ovulation following inhition of FSH with equine follicular fluid in the mare. Theriogenology. $v .26,733-$ $747,1985$.

BERGFELT, D.R.; GINTER, O.J. Ovarian, uterine and embryo dynamics in horses versus ponies. Journal of Equine Veterinary Science, v.16, n.2, p.66-72, 1996.

BOSSUT, D.F.B. Eletroacupucture-induced analgesia in sheep: Measurement of cutaneous pain threshoud and plasma concentration of prolactinand $\beta$-endorphin immunoreactivity. American Journal of Veterinary Research, v.47, p.669-676, 1986

CALDAS, M.C.S., PERDigÃO, F.R.A., ROSA E SILVA, A.A.M. Concentração de progesterona plasmática em éguas da raça "Brasileiro de Hipismo" no período pós-parto. Ars Veterinária, v.6, p.151-158, 1990.

CAIADO, J. R. C.; FONSECA, F. A.; SILVA, J. F. S.; FONTES, R. S. Tratamento de éguas receptoras de embriões visando sua utilização no segundo dia pós-ovulação Revista Brasileira de Zootecnia. v.36, n.2, p.360-368, 2007.

CARMO, M.T.; ALVAREGA, M.A Evoluções da transferência de embriões no Brasil. Acta Scientiae Veterinariae, v. 31. p. 280, 2003.

CASTRO, R.P.R.. Influência de aspectos reprodutivos e hormonais de éguas doadoras e receptoras de embriões da raça Campolina sobre a taxa de gestação e morte embrionária. Dissertação de Mestrado em Reprodução, Programa de Pós-Graduação em Medicina Veterinária, Universidade Federal Fluminense, Niterói, RJ. 70p, 2005.

COCHRAN, W. G. Técnicas de amostragem. Rio de Janeiro. Fundo de Cultura, 555p, 1955.

CROWDER, M. E., R. D. HERRING, AND T. M. NETT. Rapid recovery of gonadotroph function after down-regulation of receptors for $\mathrm{GnRH}$ in ewes. Journal Reproduction Fertility., v.78, p.577-585. 1986.

DAELS, P.F. et al., Effects of flunuxin meglumine on endotoxin-induced prostaglandin $F_{2 \alpha}$ secretion during early pregnancy in the mare. American Journal Veterinary Research. v.52, p. 276-281,1991.

DOUGLAS, R.H.; BURNS, P.J.; HERSHMAN, L. Physiological and commercial parameters for producing progeny for subfertile mares by embryo transfer. Equine Veterinary Journal, v.3, p.111-114, 1985. 
DUCHAMP, G., BOUR, B., COMBARNOUS, Y., PALMER, E. Alternative solutions to hCG induction of ovulation in the maré. Journal of Reproduction and Fertility Supplement, v.35, p. 221-228, 1987.

FITZGERALD, B. P., PETERSON, K. D., SILVIA, P. J. Effect of constant administrationof a gonadotropin-releasing hormone agonist on reproductive activity in mares:Preliminary evidence on suppression of ovulation during the breeding season. American Journal Veterinary Researchv.54, p.1746-1751, 1993.

FLEURY, J.J. O dia da colheita na taxa de recuperação de embriões em eqüinos em uma central de transferência de embriões comercial. Arquivos Faculdade de Veterinária. v.26, p.268, 1998.

FORTUNE, JE. Selection and maintenance of the dominant follicle: An introduction. Biology of Reproduction, v.65, p. 637, 2001.

FORTUNE, J.E. Ovarian follicular growth and development in mammal. Biology of Reproduction, v.50, p. 225-232, 1994.

FRASER, H. M. Luteinizing hormone-releasing hormone and fertility control. Oxford, Revista Reproductive Biology, v.3, p.1-48, 1981.

FREEDMAN, L.J.; GARCIA, M.C.;GINTHER, O.J., Influence of ovaries and photoperiod on reproductive in the mare. Journal Reproduction Fertility, Supplement. v.27, p.79$86,1979 a$.

FREEDMAN, L.J., GARCIA, M.C. \& GINTHER, O.J.,. Influence of photoperiod and ovaries on seasonal reproductive activity in mares. Biology of Reproduction, v.20, p.567-86, 1979b.

GARCIA, M.C. \& GINTHER, O.J.,. Effects of ovariectomy and season on plasma LH in mares. Endocrinology, v.98, n.4, p.958-962, 1976.

GINTHER, O.J., Reproductive Biology of The mare: basic and applied aspects. (2ed) . Equiserves, Cross Plains, Wisconsin. 642p,1992.

GINTHER, O. J. Embryonic loss in mares: Incidence, time of occurrence and hormonal involvement. Theriogenology, v.23, p.77-83, 1985.

GINTHER, O. J. Selection of the dominat follicle in cattle and horses. Animal Reproduction Science, v.60-61, p.61-79, 2000.

GINTHER, O. J. \& BERGFELT, D.R. Growth of animal follicles and concentrations of FSH during the equine estrous cycles. Journal of Reproduction and Fertility, v.99, p.105-111, 1993.

GOERITZ, F.; et al. Seasonal timing of sperm production in roe deer: interrelationship among changes in ejaculate parameters, morphology and function of testis and accessory glands. Theriogenology, v.59, p.1487-1502, 2003.

HAFEZ, E.S.E. Reproduction in farm animals, 7. ed, Philadelphia: Lea \& Febiger, 2000.

HAFEZ, E.S.E.; HAFEZ, B Reprodução Animal, 7 ed., Manole, U.S.A.2003.

HART,P.J. et al. Seasonal variation in hipothalamic content of GnRH, pituitary content of LH and FSH in the mare. Biology of Reproduction. v.30, p. 1055-1062, 1984. 
HINRICHS, K.; KENNEY, M. Effect of timing of progesterone administration on pregnancy rate after embryo transfer in ovariectomized mares. Journal of Reproduction and Fertility, v.35, p.439-443, 1987.

HIRSHFIELD, A.N. Comparison of granulose cell proliferation in small follicles of hypophysectomized, prepuberal and mature rats. Biology of Reproduction, v.32, p.979-987, 1985.

HOLTAN, D.W., NETT, T.M., ESTERGREEN, V.L. Plasma progestins in pregnant, postpartum and cycling mares. Journal Animal Science, v.40, n.2, p.251-260, 1975.

HUGHES, J.P. et al. The estrous cycle and selected functional and pathologic ovarian abnormalities in the mare. Veterinary Clinic North American (Large Animal Pract.). v.2, n. 22 , p. $225-239,1980$.

HUGHES, J.P. et al., Estrous cycle and ovulation in the mare. Journal American Veterinary Medicine. v.161, p.1367-1374, 1972.

IRVINE, D. S., DOWNEY, B. R., PARKER, W. G., SULLIVAN, J. J. Duration of oestrus and time of ovulation in mares treated with synthetic Gn-RH (AY-24,031). Journal

Reproduction Fertility Supplement, v.23, p.279-283, 1975.

KATILIA, T, OIJALA, M., KOTILAINEN, T. et al. Embryo transfer in subfertile mares. Acta Veterinaria Scandinavica., v.30, p.329-333, 1989.

KENDALL, D. E. Clinical significance of acupuncture mechanism with respect to internal medicine e treating infertility In: INTERNATIONAL CONGRESS ON VETERINARY ACUPUNCTURE, 25, 1999, Lexington Anais... Lexington: The International Veterinary Acupuncture Society, p.197-239, 1999.

KLIDE,A.M. Veterinary acupuncture. University of Pennsylvania Press, Philadelphia, 297 p., 1977

KLEIN, S.L. \& NELSON, R.J Influence of social factors on immune function and reproduction. Revista of Reproduction, v.4, p.68-178, 1999.

LIN, J.H.; CHEN, W.W.; WU, L.S. Acupuncture treatment for animal reproductive disorders, 2001 Disponível em: http://users.med.auth.gr/ karanik/english/articles/lin99rep.html>. Acesso em 27 de março de 2008.

LIN, J.H. Effects of electroacupuncture and gonadotropin-releasing hormones treatment on hormonal changes in anoestrus sows. American Journal of Chinese Medicine, v.16, p.117126, 1998.

Luna, SPL, Joaquim JG, M. Minichelli, MA Alvarenga, CM Barros. O papel do BAI HUI accupoint para indução de luteólise em éguas. Proc. Inter anuais. Congress Veterinary Acupuncture. vol. 25. p. 29, 1999.

MACCIOCIA, G. Fundamentos da Medicina Chinesa. Ed. Roca, São Paulo,1996, 932p.

MADUREIRA, E. H. Estudo comparativo da sincronização do estro por norgestometPGF2a ou Syncro-Mate B, em gado Zebu (Bos indicus) e Caracu X Zebu (Bos taurus $X$ Bos indicus). 133 f. Dissertação (Doutorado) - Faculdade de Medicina Veterinária e Zootecnia, Universidade de São Paulo, São Paulo, 1995. 
MALVEN, P.V. Effect of naloxone and acupuncture treatment on plasma concentration of LH in sheep. Journal of Endocrinology, v.101, p.76-80, 1984.

MALVEN, P.V. Searching for $r$ inhibitory action of blood-borne $\beta$-endorphin on LH release. Journal of Reproduction and Fertility, suppl. 34, p.09-16, 1987.

MANN, F. Acupuntura. A arte Chinese de curar. SP: Hemus, 1982, 208p

McCRACKEN, J.A ., EDWARD, E.C. and LAMSA, J.C. Luteolisys: A Neuroendocrine-mediated Event. Physiology Revista. v.79, n.2, p.263-323, 1999.

McCUE, P., HUDSON, J.J., BRUEMMER, J.E., SQUIRES, E.L. Efficacy of hCG at Inducing Ovulation: A New Look at an Old Issue. 50th Annual Convention of the American Association of Equine Practitioners, p. 1492-1207, 2004.

MCKINNON, A. O., NOBELLIUS, A. M., TARRIDA DEL MARMOL FIGUEROA, S. SKIDMORE, J., VASEY, J. R., TRIGG, T. E. Predictable ovulation in mares treated with an implant of the GnRH analogue deslorelin. Equine Veterinary Journal, v.25, p.321-323, 1993.

MEDEIROS, A.S.L.; SILVA JÚNIOR, B.L.; MELO, C.M.; CARMO, M.T.; PAPA, F.O.; PUOLI FILHO, J N P; ARAÚJO, G.H. M; ALVARENGA, M.O. Utilização do extrato de pituitária eqüina como agente indutor da ovulação em éguas. In: XIX REUNIÃO ANUAL DA SBTE, 2005, Angra dos Reis. Acta Scientiae Veterinariae. v. 30, p. 195, 2005.

MEINERT, C., J. F. SILVA, I. KROETZ, E. KLUG, T. E. TRIGG, H. O. HOPPEN, AND W. JÖCHLE. Advancing the time of ovulation in the mare with a short-term implant releasing the $\mathrm{GnRH}$ analogue deslorelin. Equine Veterinary Journal, v.25, p.65-68, 1993.

MELO, C.M. Efeito do armazenamento por 24 horas em diferentes sistemas de refrigeração sobre a viabilidade e fertilidade de sêmen congelado eqüino. Botucatu, . Dissertação (Mestrado) - Faculdade de medicina Veterinária e Zootecnia, Universidade Estadual Paulista, 104 p., 2005.

MONAHAN, M. W., AMOSS, M. S., ANDERSON, H. A., VALE, W. Synthetic analogs of the hypothalamic luteinizing hormone-releasing factor with increased agonist of antagonist properties. Biochemistry v.12, p.4616-4620, 1973.

MUMFORD, E. L., SQUIRES, E. L., JÖCHLE, W., HARRISON, L. A., NETT, T. M., TRIGG, T. E. Use of deslorelin short-term implants to induce ovulation in cycling mares during three consecutive estrous cycles. Animal Reproduction Science v.39, p.129-140, 1995.

NETT, T.M., PICKETT, B.W., SEIDEL JR, G.E. Levels of luteinizing hormone and progesterone during the estrous cycle and early pregnancy in mares. Biology of Reproduction, v.14, p.412-415, 1976.

OSBORNE, V.E.. Na analysis of the pattern of ovulation as it occurs in the annual reproductive cycle of the mare in Australia. Australian Veterinary Journal. v. 42, p.149-154,1966.

PALMER, E. \& QUELLIER, P. Uses of LHRH and analogues in the mare. In: Proc. 5th International Congress Animal Reproduction Artificial Insemination, Dublin, Irlanda. P.339-346, 1988.

PALMER, E. Induction of ovulation. In: McKinnon, A.O. \& Voss, J.L. Equine Reproduction. Malvern: Lea \& Febiger, p.344-347, 1993. 
PALMER, E.; JOUSSET, B. Synchronization of oestrus in mares with a prostaglandin analogue and hCG. Journal of Reproduction and Fertility, v. 23, p. 269-274, 1975. Supplement.

PASHEN, R.L., LASCOMBES, F.A., DARROW, M.D. The application of embryo transfer to polo ponies in Argentina. Equine Veterinary Journal, v.15, p.119-121, 1993.

PIERSON, R.A . \& GINTHER, O. J.. Ultrasonic evaluation of the ovaries in mares and heifers. Proc. 10 $^{\text {th }}$ Congress Animal Reproduction. Artificial Insemination v. 3, p. 496-498, 1984.

REDMER, D.A .; REYNOLDS, L.P. Angiogeneses in the ovary. Revista Reproduction. v.1, p.182-192, 1996.

RIERA, F.L., McDONOUGH, J. Commercial embryo transfer in polo ponies in Argentina. Equine Veterinary Journal, v.15, p.116-118, 1993.

ROSS, J. Zang fu: the organ systems de TCM. Churchill Livingstone, Edinburgh, p.12-18, 1985.

RUSSE, I. Oogenesis in cattle and sheep. Bibliotheca Anatomica, v.24, p.77-92, 1983.

SAMPER, J.C. JENSEN, S., SERGENAT, J., Timing of induction of ovulation in mares treated with ovuplant or chorulon. Journal of equine veterinary Science, v.22, n.7, p.320-323, 2002.

SAMPER, J.C. Ultrasonographic Appearance and the Pattern of Uterine Edema to Time Ovulation in Mares, Aaep Proceedings, v.43, p.189-191, 1997.

SAN, Y. University of Traditional Chinese Medicine: principles and theories of TCM, Santa Monica, Calif, 1996.

SANDOW, J. The regulation of LHRH action at the pituitary and gonadal receptor level: A review. Psychoneuroendocrinology, v.8, p.277-297, 1983.

SHARP, D.C. Environmental influences on reproduction in horses. Veterinary Clinic North American. v. 2, p. 207-223, 1980.

SHARP, D. C.; CLEARVER, B. D.; DAVIS, S. D. Photoperiod. In: Micknnon A.O.; Voss J.L. (eds.). Equine reproduction. Philadelphia: Lae \& Fieber, p.179-185, 1993.

SHARP, D.C. The early fetal life of the equine conceptus. Animal Reproduction Science, v.60-61, p.679-689, 2000.

SHARP, D.C. \& GINTHER, O.J., Stimulation of follicular activity and estrous behavior in anestrous mares with ligth and temperature. Journal Animal Science. v.41, p.1368-1372, 1975.

SHOEN, A.M. Acupuntura veterinária da arte antiga a medicina moderna. Ed Roca, São Paulo, 2006, 603p.

SILVA, J. F. S.; CNOP, F. P.; SÁNCHEZ2, R. J. R.; VIANNA, S.A. B., SOUZA, G.V.; ELIGIO, C. T.;RIBAS, J. A. S.; COSTA, D. S. Avaliação da dinâmica útero-ovárica da égua sob o efeito de um implante subcutâneo de micro-cápsulas de polihidroxibutirato contendo progesterona.Revista Portuguesa de Ciência Veterinárias. v.101, p.225-230, 2006. 
SITERMAN, S.; ELTES, F.; WOLFSON, V.; et al. Does acupuncture treatment affect sperm density in males with very low sperm count? A pilot study. Andrology, v.32, p.31-39, 2000.

SOUZA, J.A.T.; GACEK, F.; OLIVEIRA, J.B. Características do corpo lúteo e progesterona plasmática no ciclo estral de potras da raça Brasileiro de Hipismo. Arquivo da Faculdade de Veterinária da UFRGS, v.27, p.298, 1999.

SQUIRES, E.L., MORAN, D. M., FARLIN, M. E., JASKO, D. J., KEEFE, T. J., MEYERS, S. A., FIGUEIREDO, E., MCCUE, P. M., JÖCHLE, W. Effect of dose of GnRH analog on ovulation in mares. Theriogenology, v.41, p.757-769, 1994.

SQUIRES, E.L., MCCUE, P.M., VANDERWALL, D. The current status of equine embryo transfer. Theriogenology, v.51, p.91-104, 1999.

SQUiRES, E. L., WALLACE, R. A., VOSS, J. L., PICKETT, B. W., SHIDELER, R. K.

. The effectiveness of PGF2a, HCG, and GnRH for appointment breeding of mares. Journal of Equine Veterinary Science, v.1, p.5-9, 1981.

SULLIVAN, J.J., PARKER, W.G., LARSON, L.L. Duration of estrus and ovulation time in nonlactating mares given human chorionic gonadotropin during three successive estrous periods. Journal of American Veterinary Medical Association, v.162, p.895-898, 1973.

SUMANO, L.M.; LÓPEZ, B.G. Acupuntura Veterinária. México: intermericana, 346p, 1990.

SWANN, R.T., BRUCE, N.W. Oxygen consumption, carbon dioxide production and progestagen secretion in the intact rat ovary of the day-16 pregnent rat. Journal Reproduction Fertilitity. v.80, p. 599-605, 1987.

TAROUCO, A. K., et al., 1995. Estacionalidade reprodutiva de éguas abatidas em Pelotas-RS. Arquivos da Faculdade de Veterinária UFRGS, v.23, p.26-42. Malvern: Lea \& Febiger, p.344-347, 1993.

VANDERWALL, D. K., JUERGENS, T. D., WOODS, G. L. Reproductive performance of commercial broodmares after induction of ovulation with hCG or Ovuplant ${ }^{\mathrm{TM}}$ (deslorelin). Journal Equine Veterinary Science, v.21, p.539-542, 2001.

VERONESI, M.C., BATTOCHIO, M., FAUSTINI, M., GANDINI, M., CAIROLI, F.Relationship between pharmacological induction of estrous and/or ovulation and twin pregnancy in the Thoroughbred mares. Domestic Animal Endocrinology, v.25, p.133-140, 2003.

UNIVERSIDADE FEDERAL DE VIÇOSA - UFV. SAEG - Sistema de análises estatísticas. Versão 7.0. Viçosa, MG. 150p, 1997.

WESSON, J, A. \& GINTHER, O.J., Influence of season and age on reproductive activity in pony mares on the basis of a slaughterhouse study. Journal Animal Science, v.52, p.119-129, 1981.

WOODS, G.L., GINTHER, O.J. Induction of multiple ovulations during the ovulatory season in mares. Theriogenology, v.20, p.347-375, 1983.

XINONG, C. Acupuntura e Moxabustão Chinesa. Ed. Roca, SP. 1999, 396p.

YOUNG, K.A., NELSON, R.J. Meditation of seasonal testicular regression by apoptosis. Reproduction, v.122, p.677-685, 2001. 
ZILBERSTEIN, ZAKUT, M., H., NAOR, Z. Coincidence of down-regulation and desensitization in pituitary gonadotrophs stimulated by gonadotropin releasing hormone. Life Science, v.32, p.663-669, 1983. 